\title{
FAST MYOCARDIAL RECOVERY ENSURED BY THE COMBINED USE OF V-A ECMO and IMPELLA CP IN CARDIOGENIC SHOCK RELATED TO A PHEOCHROMOCYTOMA CRISIS
}

\author{
Andrea Montalto ${ }^{1}$, Francesca Nicolo', ${ }^{2}$, Vincenzo Polizzi ${ }^{2}$, Marina Comisso $^{2}$, and Francesco \\ Musumeci $^{2}$ \\ ${ }^{1}$ San Camillo Forlanini Hospital \\ ${ }^{2}$ Affiliation not available
}

April 28, 2020

\begin{abstract}
Pheochromocytoma is a rare catecholamine-secreting tumor derived from chromaffin cells in the adrenal glands. A pheochromocytoma 'crisis' (PCC) can cause haemodynamic instability and end-organ damage or dysfunction. An excessive stimulation of cardiac myocytes could lead to myocardial damage with cardiogenic shock (CS). Use of mechanical circulatory support (MCS) might find an indication in this scenario as a bridge to myocardial recovery. We present the case of a patient successfully supported with ECMO (ExtraCorporeal Membrane Oxygenation) combined with IMPELLA CP heart pump (Abiomed Danvers, MA), for left ventricular (LV) unloading. MCS was used to favour myocardial recovery and avoid cardiac remodeling.
\end{abstract}

\section{Introduction}

Pheochromocytoma related cardiomyopathy could be lead to a refractory CS for that a rescue procedure with an Extracorporeal Life Support (ECLS) application, such as ECMO, to sustain the circulation and the organ perfusion giving time to the myocardium for complete recovery, is mandatory. A few cases of patients suffering from pheochromocytoma-induced CS requiring MCS have been previously reported in literature [1], but no case approached with a combined use of ECMO and Impella (for LV unloading). We describe the first successful treatment of a pheochromocytoma-induced CS with the combined use of peripheral V-A ECMO and IMPELLA CP, with subsequent complete and fast recovery of the myocardial function.

\section{Case Report:}

A 28-year old female was admitted to our Hospital with ventricular arrhythmia, hypotension and respiratory failure secondary to pulmonary oedema. Blood pressure was 70 / $40 \mathrm{mmHg}$ with heart rate being 130 beats / min and significant ST elevation in V1-V3 leads. Despite inotropic and vasoconstrictor support (noradrenaline $0.05 \mu \mathrm{g} / \mathrm{kg} / \mathrm{min}$ and dobutamine $10 \mu \mathrm{g} / \mathrm{kg} / \mathrm{min}$ ), the echocardiogram revealed a poor biventricular function (left ejection fraction $[\mathrm{EF}]<25 \%$ ). Blood test documented elevated troponin-I levels $(54,7 \mathrm{ng} / \mathrm{mL})$. Because of the worsening hemodynamic instability and metabolic acidosis, mechanical ventilation was started and a V-A ECMO device was implanted through the surgical cannulation of the right femoral artery (Return, 17 French BIO-MEDICUS TM cannula) and the right femoral vein (Access, 21 French Multi-Stage BIO-MEDICUS? cannula). A 9 French reperfusion cannula was distally inserted in the main femoral artery to prevent limb ischemia. Therefore, the unloading of the LV was obtained by inserting an IMPELLA-CP, through the left femoral artery. A trans-aortic $2,5 \mathrm{~L} / \mathrm{m}$ flow was obtained. Heparin was continuously admin- 
istrated to maintain activated clotting time between 150 and 200 sec. An emergency coronary angiography detected patent coronary arteries. An endomyocardial biopsy was also performed to exclude acute myocarditis. The urinary catecholamine levels were several times higher than normal; Epinephrine $2980 \mu \mathrm{g} /$ day (normal range2-14 $\mu \mathrm{g} /$ day); Norepinephrine $3876 \mu \mathrm{g} /$ day (normal range 230-120 $\mu \mathrm{g} /$ day); Homovanillic acid $75 \mathrm{mg} /$ day (normal renage $<15 \mathrm{mg} /$ day); Vanilmandelic acid $85,5 \mathrm{mg}$ /day (normal range $<8 \mathrm{mg} /$ day). A subsequent abdominal computed tomography revealed the presence of a $5 \mathrm{~cm}$ nodular lesion within the left adrenal gland [Fig. 1], highly suggestive for the diagnosis of pheochromocytoma. A pharmacological therapy comprehensive of alpha- and beta-blockade was therefore started. A very fast recovery was observed and the weaning from ECMO was started after only 24 hours of full support; the patient was discontinued from ECLS on day 4. The IMPELLA-CP was then switched to $1,5 \mathrm{~L} / \mathrm{m}$ flow, on day 5 . On day 6 , it was safely removed [Fig 2] and a completely recovery of $\mathrm{EF}$ was assessed by echocardiographic evaluation ( $\mathrm{EF}>60 \%)$. The patient underwent adrenalectomy 3 weeks after the initial emergency presentation and the histological examination confirmed the diagnosis of pheochromocytoma. The post-procedural course was uneventful and 10 days later the patient was discharged from our department.

\section{Discussion}

The mechanisms underlying the biventricular dysfunction following PCC are not well established. Some proposed mechanisms include coronary spasm with corresponding myocardial focal necrosis [2], direct cellular toxicity by increasing intracellular calcium concentration [3], damage induced by reactive oxygen species [4], and myocardial stunning due to receptor desensitization or down-regulation [5]. The ECMO is the largely used device for the management of CS, but highly increases the afterload of the LV worsening the pulmonary edema and triggering inflammatory reactions [6] whose combined effects If not interrupted, can ultimately lead to a chronic dilated cardiomyopathy. An effective strategy could be achieved by using an axial flow pumps such as the Impella system that ensures unloading of the LV throughout the cardiac cycle, decrease total mechanical work and myocardial oxygen demand, while lowering WS and improving subendocardial coronary blood flow. Hekimian et al reported several cases managed by ECMO implantation [7], while Riester et al. [8 8 described Impella device implantation as first choice. Our patient was haemodinamically instable, so ECMO implantation was immediately performed, rather than Impella implantation alone. Our case highlights the importance of combined treatment in these patients to achieve an early recovery. As reported, we had significant improvement in ventricular EF after only 24 hours of MCS. Weaning from ECMO was started after 48 hours, allowing ECMO removal within 4 days. The weaning from the IMPELLA has been slightly postponed ensuring support in the early stages of ECMO removal. After only 6 days from the implant, the IMPELLA was removed and a complete recovery of both ventricles was observed. These

findings suggest that LV unloading by Impella support in addition to V-A ECMO may be particularly effective in ensuring rapid recovery of myocardial function, following catecholamine-mediated cardiomyopathy.

Conflict of interest: none declared.

\section{References}

1. Hekimian G, Kharcha F, Brechot N, Schmidt M, Ghander C, Lebreton G, Girerd X, Tresallet C, Trouillet JL, Leprince P, Chastre J, Combes A, Luyt CE. Extracorporeal membrane oxygenation for pheochromocytoma-induced cardiogenic shock. Ann. Intensive Care 2016; 6:117.

2. Simons M, Downing SE. Coronary vasoconstriction and catecholamine cardiomyopathy. Am Heart J 1985; 109(2):297-304.

3. Opie LH, Walpoth B, Barsacchi R. Calcium and catecholamines: relevance to cardiomyopathies and significance in therapeutic strategies.J Mol Cell Cardiol 1985; 17(Suppl 2):21-34.

4. Costa VM, Carvalho F, Bastos ML, Carvalho RA, Carvalho M, Remiao F. Contribution of catecholamine reactive intermediates and oxidative stress to the pathologic features of heart diseases. Curr Med Chem 2011;18(15):2272-314.

5. Rosenbaum JS, Billingham ME, Ginsburg R, Tsujimoto G, Lurie KG, Hoffman BB. Cardiomyopathy in a rat model of pheochromocytoma. Morphological and functional alterations. Am J Cardiovasc Pathol 1988;1(3):389-99. 
6. Tschope C, Van Linthout S, Klein O, Mairinger T, Krackhardt F, Potapov EV, Schmidt G, Burkhoff D, Pieske B, Spillmann F. Mechanical Unloading by Fulminant Myocarditis: LV-IMPELLA, ECMELLA, BI-PELLA, and PROPELLA Concepts. J Cardiovasc Transl Res 2019; 12:116-123.

7. Hekimian G, Kharcha F, Brechot N, Schmidt M, Ghander C, Lebreton G, Girerd X, Tresallet C, Trouillet JL, Leprince P, Chastre J, Combes A and Luyt CE. Extracorporeal membrane oxygenation for pheochromocytoma-induced cardiogenic shock. Ann. Intensive Care2016; 6:117.

8. Riester A, Weismann D, Quinkler M, Lichtenauer UD, Sommerey S, Halbritter R, Penning R, Spitzweg C, Schopohl J, Beuschlein F, Reincke M. Life-threatening events in patients with pheochromocytoma.Eur J Endocrinol 2015; 173(6):757-64.

\section{Legends:}

Figure 1: Image of abdominal computed tomography showing the presence of a nodular lesion of $5 \mathrm{~cm}$ on the left adrenal gland.

Figure 2: Visualization of the progressive steps of weaning from ECMO (red line) and IMPELLA (blue line). POD: post operative day.

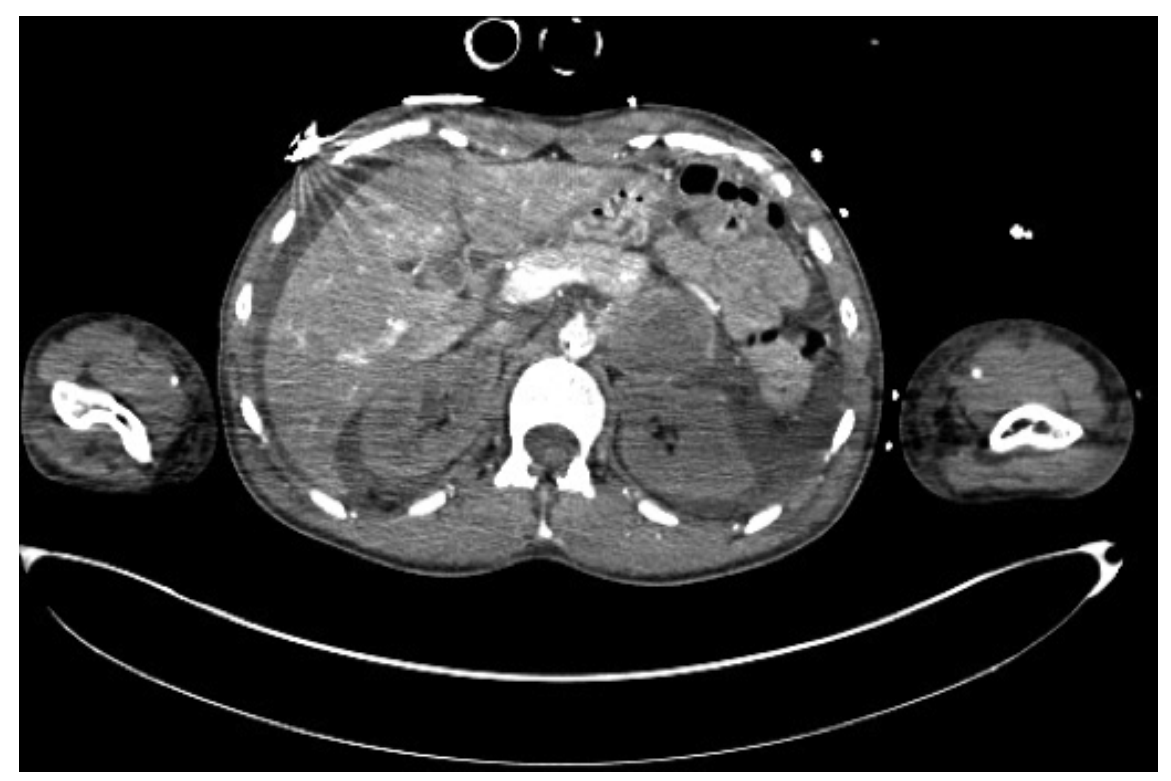




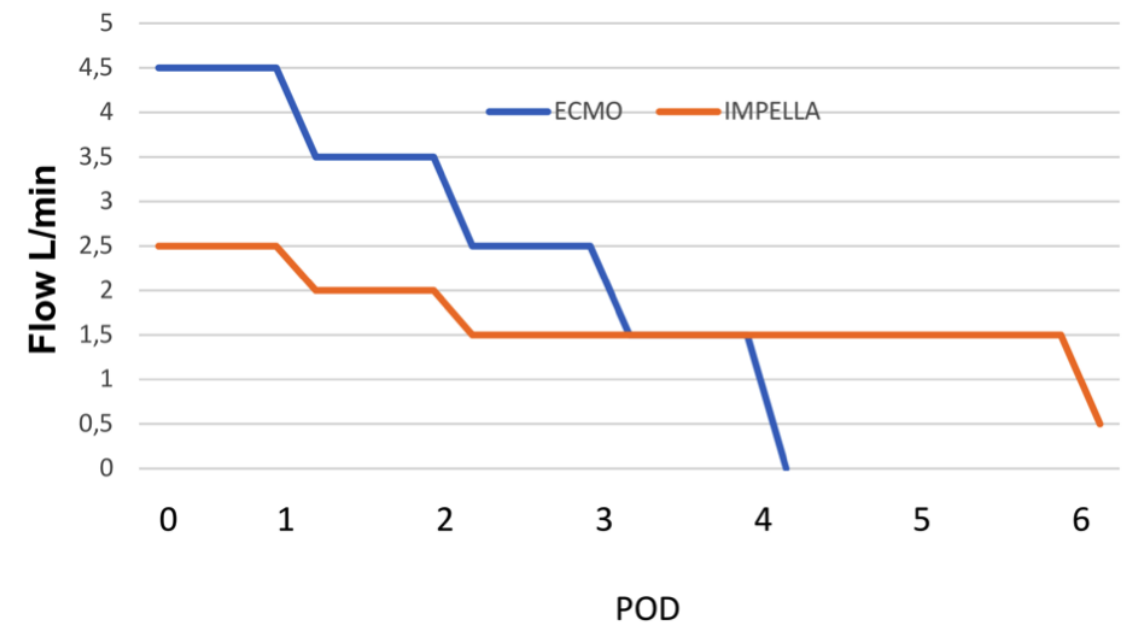

